Supporting information

\title{
Two cyanide-bridged $\mathrm{Mn}^{\mathrm{II}}-\mathrm{Nb}^{\mathrm{IV}}$ coordination chain ferrimagnets promoted by interchain ferromagnetic interactions
}

Michał Magott, ${ }^{\dagger}$ Hanna Tomkowiak, ${ }^{\star}$ Andrzej Katrusiak, ${ }^{\star}$ Wojciech Nitek, ${ }^{\dagger}$ Barbara Sieklucka $^{\dagger}$ and Dawid Pinkowicz, ${ }^{* \dagger}$

$\dagger$ Faculty of Chemistry, Jagiellonian University, Ingardena 3, 30-060 Kraków, Poland

$\$$ Faculty of Chemistry, Adam Mickiewicz University, Umultowska 89b, 61-614 Poznań, Poland

\section{Table of contents:}

Figure S1. IR spectra for 1 (black line) and 2 (red line) in the $4000-450 \mathrm{~cm}^{-1}$ (a) and 2240 $2020 \mathrm{~cm}^{-1}$ (b) range.

Table S1. Comparison of the selected crystallographic parameters for 2 collected at 100 and $200 \mathrm{~K}$ using $\mathrm{MoK} \alpha$ and $\mathrm{CuK} \alpha$, respectively.

Table S2. Details of the Continuous Shape Measure (CShM) analysis ${ }^{\text {a }}$ for the coordination spheres of $\mathrm{Nb}^{\mathrm{IV}}$ centres in $\mathbf{1}$ and $\mathbf{2}$, and for $\mathrm{W}^{\mathrm{IV}}$ centre in the tungsten(IV)-analogue of $\mathbf{1}$ $\left\{\left[\mathrm{Mn}^{\mathrm{II}}(\text { bpy })\left(\mathrm{H}_{2} \mathrm{O}\right)_{2}\right]_{2}\left[\mathrm{~W}^{\mathrm{IV}}(\mathrm{CN})_{8}\right] \cdot 6 \mathrm{H}_{2} \mathrm{O}\right\}_{n}($ ref. 19).

Figure S2. Fragments of structure of 1, showing interchain hydrogen bonding. 2,2'-bipyridine molecules and hydrogen atoms were omitted for clarity. $\mathrm{Mn}$ - pink, $\mathrm{Nb}$ - cyan, $\mathrm{C}-$ gray, $\mathrm{N}-$ blue, $\mathrm{O}-$ red.

Figure S3. Fragments of structure of 1, showing intrachain hydrogen bonds. 2,2'-bipyridine molecules and hydrogen atoms were omitted for clarity. $\mathrm{Mn}-$ pink, $\mathrm{Nb}-$ cyan, $\mathrm{C}-$ gray, $\mathrm{N}-$ blue, $\mathrm{O}-$ red.

Figure S4. Layers of crystallization water molecules between chains in $\mathbf{1}$. Only skeletons of the chains were pictured. Ellipsoids at $50 \%$ probability level. $\mathrm{Mn}$ - pink, $\mathrm{Nb}$ - cyan, $\mathrm{C}-$ gray, $\mathrm{N}-$ blue, $\mathrm{O}$ - red.

Figure S5. Fragments of structure of $\mathbf{1}$, showing $\pi$ - $\pi$ stacking between the neighboring chains. Crystallization water molecules and hydrogen atoms omitted for clarity. $\mathrm{Mn}$ - pink, $\mathrm{Nb}$ - cyan, $\mathrm{C}$ - gray, $\mathrm{N}$ - blue, $\mathrm{O}$ - red. 
Figure S6. Autostereographic projection (A. Katrusiak, J. Mol. Graphics Modell., 2001, 19, 363-367) of the crystal structure of compound 2. Hydrogen bonds are marked by cyan dotted lines.

Figure S7. Fragments of structure of 2, showing H-shaped hydrogen bonding patterns. $\mathrm{Mn}-$ pink, $\mathrm{Nb}$ - cyan, $\mathrm{C}$ - gray, $\mathrm{N}$ - blue, $\mathrm{O}$ - red.

Figure S8. Fragments of structure of $\mathbf{2}$, showing intrachain hydrogen bonding interactions. Mn - pink, $\mathrm{Nb}$ - cyan, $\mathrm{C}$ - gray, $\mathrm{N}$ - blue, $\mathrm{O}$ - red.

Figure S9. Fragments of structure of $\mathbf{2}$, showing $\pi-\pi$ interactions between chains. Crystallization water molecules and hydrogen atoms were omitted for clarity. Mn - pink, $\mathrm{Nb}$ - cyan, $\mathrm{C}-$ gray, $\mathrm{N}$ - blue, $\mathrm{O}$ - red.

Figure S10. Results of the AC magnetic susceptibility measurements for compound $\mathbf{1}\left(H_{\mathrm{AC}}=\right.$ $\left.1.5 \mathrm{Oe}, H_{\mathrm{DC}}=0 \mathrm{Oe}\right)$.

Figure S11. Results of the AC magnetic susceptibility measurements for compound $2\left(H_{\mathrm{AC}}=\right.$ $\left.1.5 \mathrm{Oe}, H_{\mathrm{DC}}=0 \mathrm{Oe}\right)$.

Figure S12. (a) $\chi^{-1}(T)$ dependence for 1 (black) and 2 (red) with Curie-Weiss fits in $200-300$ $\mathrm{K}$ range (dotted lines) and the best fits to the model described in the text in the $50-300 \mathrm{~K}$ range (solid lines); (b) the scheme showing how the $-\mathrm{Mn}_{2}-\mathrm{Nb}-\mathrm{Mn}_{2}-\mathrm{Nb}-$ molecule has been closed into a loop in order to roughly approximate the magnetic behaviour of an infinite $-\mathrm{Mn}_{2}-\mathrm{Nb}-$ chain at temperatures above $50 \mathrm{~K}$. 
Figure S1. IR spectra for 1 (black line) and 2 (red line) in the $4000-450 \mathrm{~cm}^{-1}$ (a) and 2240 $2020 \mathrm{~cm}^{-1}$ (b) range.
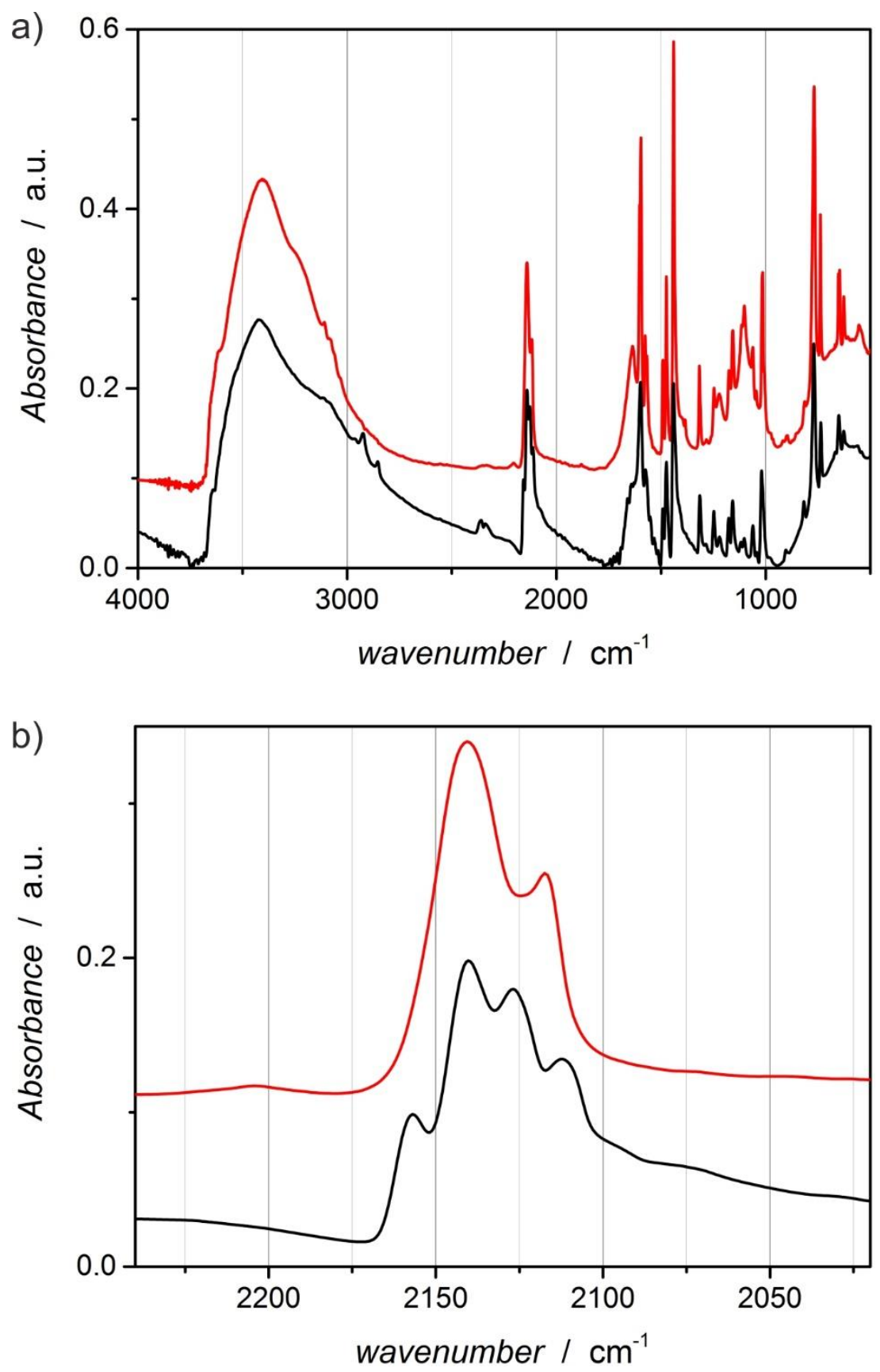
Table S1. Comparison of the selected crystallographic parameters for 2 collected at 100 and $200 \mathrm{~K}$ using $\mathrm{MoK} \alpha$ and $\mathrm{CuK} \alpha$, respectively.

\begin{tabular}{|c|c|c|}
\hline Temperature & $100 \mathrm{~K}$ & $200 \mathrm{~K}$ \\
\hline Instrument & Bruker D8 Quest Eco & SuperNova \\
\hline Detector & Photon50 CMOS & $\mathrm{CCD}$ \\
\hline X-ray source & Mo K $\alpha$ & $\mathrm{Cu} \mathrm{K} \alpha$ \\
\hline Formula & $\mathrm{C}_{152} \mathrm{H}_{96} \mathrm{Mn}_{8} \mathrm{~N}_{56} \mathrm{Nb}_{4} \mathrm{O}_{28}$ & $\mathrm{C}_{152} \mathrm{H}_{126} \mathrm{Mn}_{8} \mathrm{~N}_{56} \mathrm{Nb}_{4} \mathrm{O}_{23}$ \\
\hline $\mathrm{FW} / \mathrm{g} \cdot \mathrm{mol}^{-1}$ & 3966.00 & 3916.24 \\
\hline Crystal system & monoclinic & monoclinic \\
\hline Space group & $P 21 / \mathrm{n}$ & $P 2{ }_{1} / \mathrm{n}$ \\
\hline$a / \AA$ & $16.944(2)$ & $16.911(1)$ \\
\hline$b / \AA$ & $54.523(7)$ & $54.510(3)$ \\
\hline $\mathrm{c} / \AA$ & $19.801(3)$ & $20.018(1)$ \\
\hline$\beta /{ }^{\circ}$ & $109.553(2)$ & 109.747(8) \\
\hline$V / \AA^{3}$ & 17289(4) & $17368(2)$ \\
\hline $\mathrm{Z}$ & 4 & 4 \\
\hline$\rho / \mathrm{g} \cdot \mathrm{cm}^{-3}$ & 1.524 & 1.498 \\
\hline Abs. coeff. $/ \mathrm{mm}^{-1}$ & 0.900 & 7.287 \\
\hline$F(000)$ & 7952 & 7912 \\
\hline Crystal / mm & $0.32 \times 0.27 \times 0.16$ & $0.15 \times 0.10 \times 0.08$ \\
\hline$\theta$ range $/^{\circ}$ & $3.18-24.62$ & $5.939-89.765$ \\
\hline Refl. collected & 130556 & 174630 \\
\hline$R_{\text {int }}$ & 0.1046 & 0.2441 \\
\hline Indep. refl. & 28576 & 37806 \\
\hline Refl. $I>2 \sigma(I)$ & 18096 & 11498 \\
\hline Parameters & 2261 & 2233 \\
\hline$G O F$ on $F^{2}$ & 1.04 & 1.094 \\
\hline$R_{1}($ refl. $I>2 \sigma(I))$ & 0.0882 & 0.1701 \\
\hline$w R_{2}$ (all refl.) & 0.2110 & 0.4953 \\
\hline Completness & 0.972 & 0.987 \\
\hline $\begin{array}{l}\text { Largest diff. } \\
\text { peak/hole / e } \cdot \AA^{-3}\end{array}$ & $2.406 /-2.416$ & $5.788 /-1.518$ \\
\hline
\end{tabular}


Table S2. Details of the Continuous Shape Measure (CShM) Analysis ${ }^{\text {a }}$ for the coordination spheres of $\mathrm{Nb}^{\mathrm{IV}}$ centres in $\mathbf{1}$ and $\mathbf{2}$, and for $\mathrm{W}^{\mathrm{IV}}$ centre in the tungsten(IV)-analogue of $\mathbf{1}$ $\left\{\left[\mathrm{Mn}^{\mathrm{II}}(\mathrm{bpy})\left(\mathrm{H}_{2} \mathrm{O}\right)_{2}\right]_{2}\left[\mathrm{~W}^{\mathrm{IV}}(\mathrm{CN})_{8}\right] \cdot 6 \mathrm{H}_{2} \mathrm{O}\right\}_{\mathrm{n}}($ ref. 19).

\begin{tabular}{lllcccc}
\hline & $\mathbf{1}$ & $\mathbf{2}(\mathrm{Nb} 1)$ & $\mathbf{2}(\mathrm{Nb} 2)$ & $\mathbf{2}(\mathrm{Nb} 3)$ & $\mathbf{2}(\mathrm{Nb} 4)$ & ref. 19 \\
\hline$S_{\mathrm{DD}}$ & 0.494 & 2.556 & 2.025 & 2.187 & 2.281 & 1.052 \\
$S_{\mathrm{SAPR}}$ & 1.645 & 0.057 & 0.116 & 0.123 & 0.071 & 0.645 \\
$S_{\mathrm{BTPR}}$ & 1.810 & 2.011 & 1.893 & 1.631 & 2.042 & 1.678 \\
\hline
\end{tabular}

${ }^{a} S_{\mathrm{DD}}, S_{\mathrm{SAPR}}, S_{\mathrm{BTPR}}$ - shape measure relatives to the triangular dodecahedron (DD), square antiprism (SAPR) and biaugmented trigonal prism (BTPR). When the respective shape measure parameter equals zero, the real geometry coincides with the idealized one.

Figure S2. Fragments of structure of 1, showing interchain hydrogen bonding. 2,2'-bipyridine molecules and hydrogen atoms were omitted for clarity. $\mathrm{Mn}$ - pink, $\mathrm{Nb}$ - cyan, $\mathrm{C}-$ gray, $\mathrm{N}-$ blue, $\mathrm{O}$ - red.

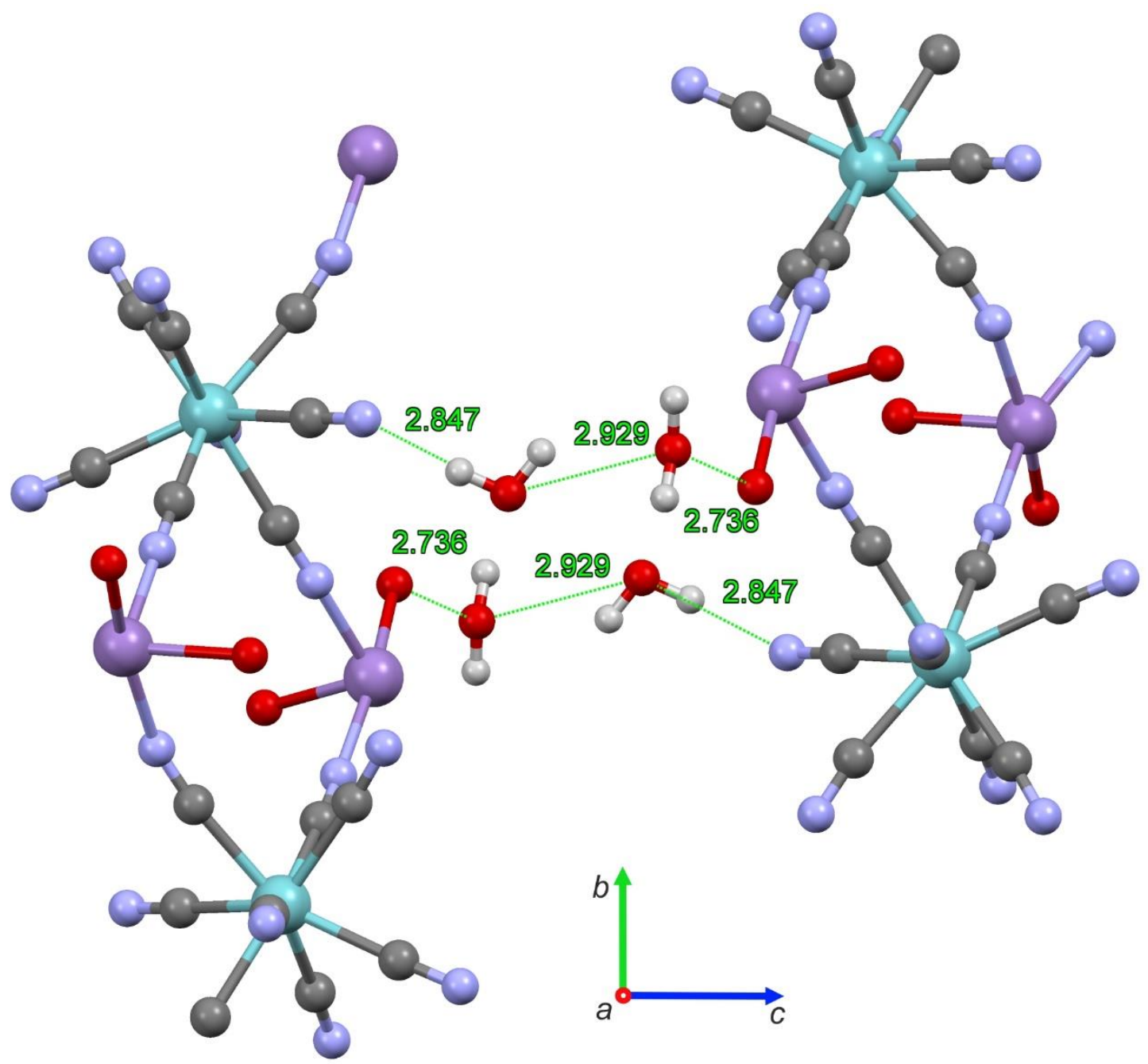


Figure S3. Fragments of structure of 1, showing intrachain hydrogen bonds. 2,2'-bipyridine molecules and hydrogen atoms were omitted for clarity. $\mathrm{Mn}-$ pink, $\mathrm{Nb}-$ cyan, $\mathrm{C}-$ gray, $\mathrm{N}-$ blue, $\mathrm{O}-$ red.

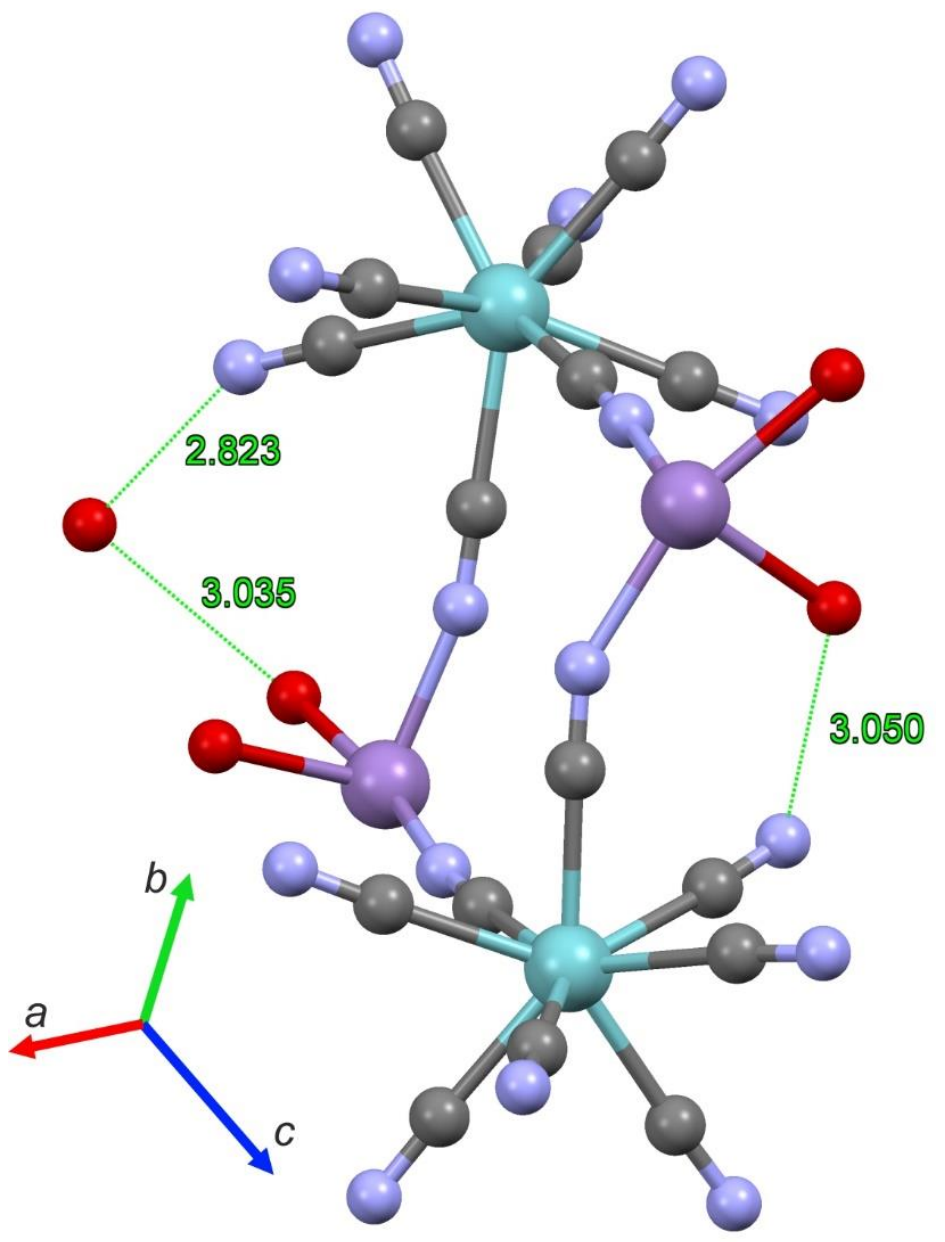


Figure S4. Layers of crystallization water molecules between chains in 1. Only skeletons of the chains were pictured. Ellipsoids at $50 \%$ probability level. $\mathrm{Mn}$ - pink, $\mathrm{Nb}$ - cyan, $\mathrm{C}$ - gray, N blue, $\mathrm{O}$ - red.

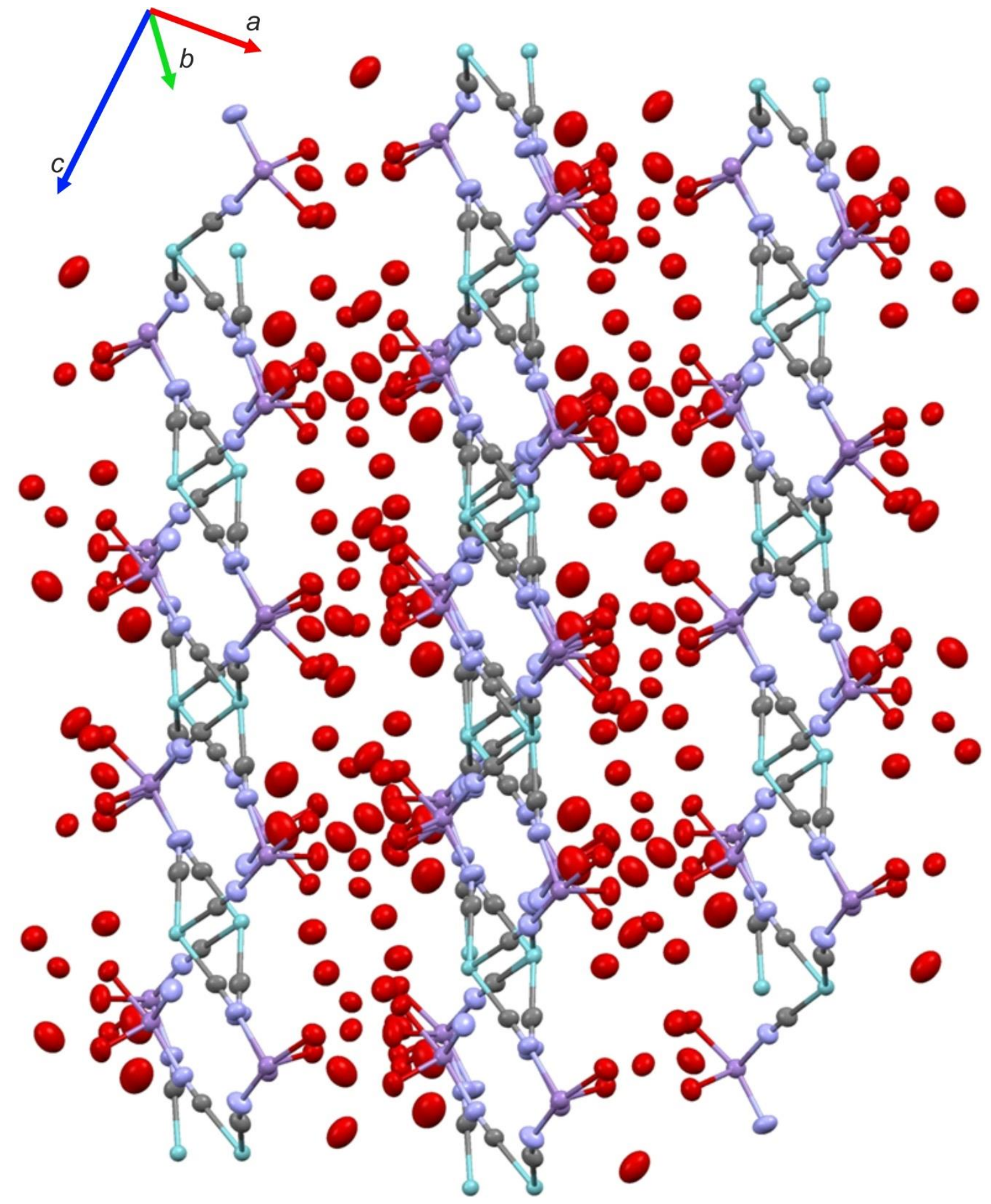


Figure S5. Fragments of structure of $\mathbf{1}$, showing $\pi-\pi$ stacking between the neighboring chains. Crystallization water molecules and hydrogen atoms omitted for clarity. $\mathrm{Mn}$ - pink, $\mathrm{Nb}$ - cyan, $\mathrm{C}$ - gray, $\mathrm{N}$ - blue, $\mathrm{O}$ - red.

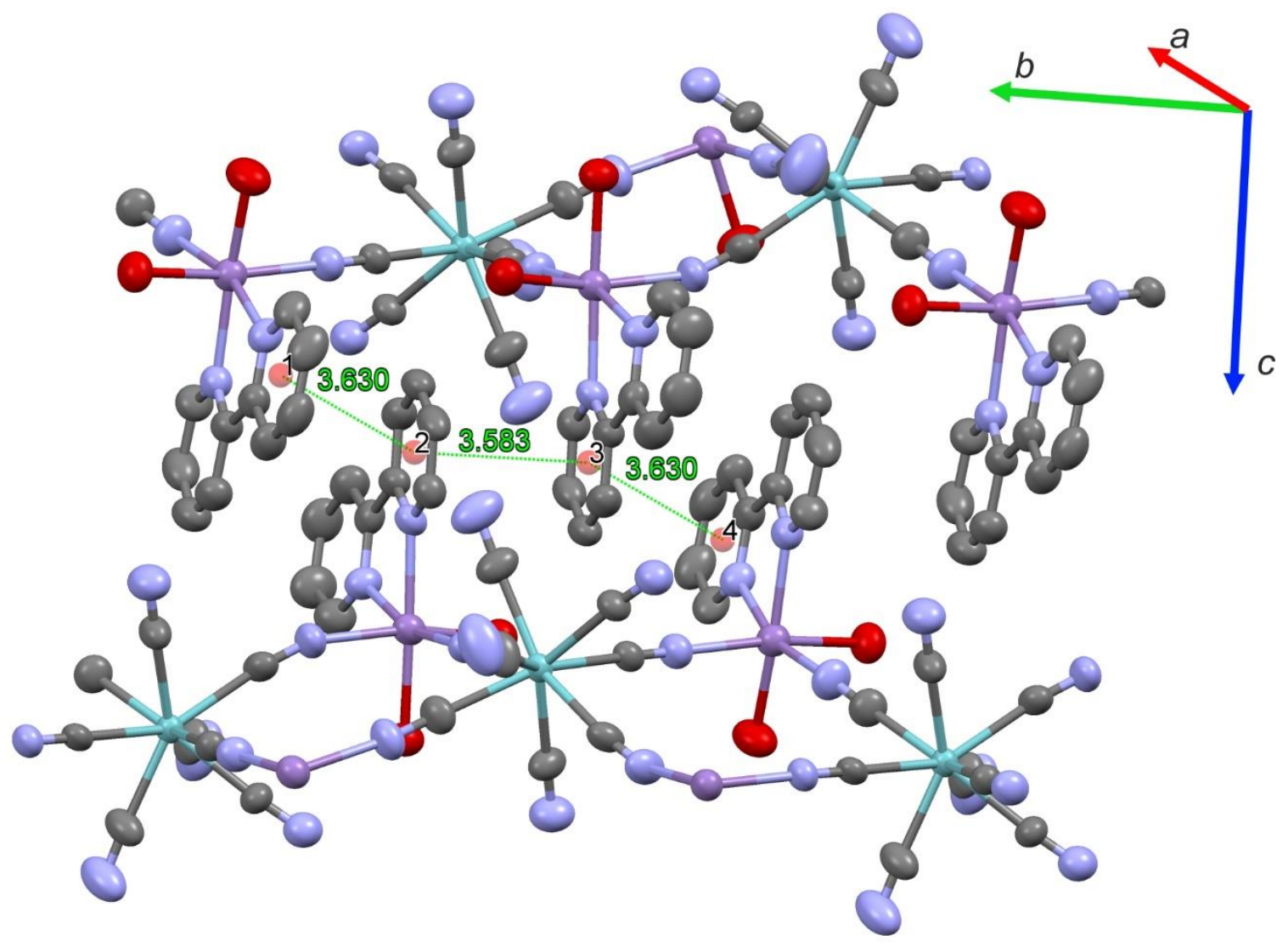


Figure S6. Autostereographic projection (A. Katrusiak, J. Mol. Graphics Modell., 2001, 19, 363-367) of the crystal structure of compound 2. Hydrogen bonds are marked by cyan dotted lines.

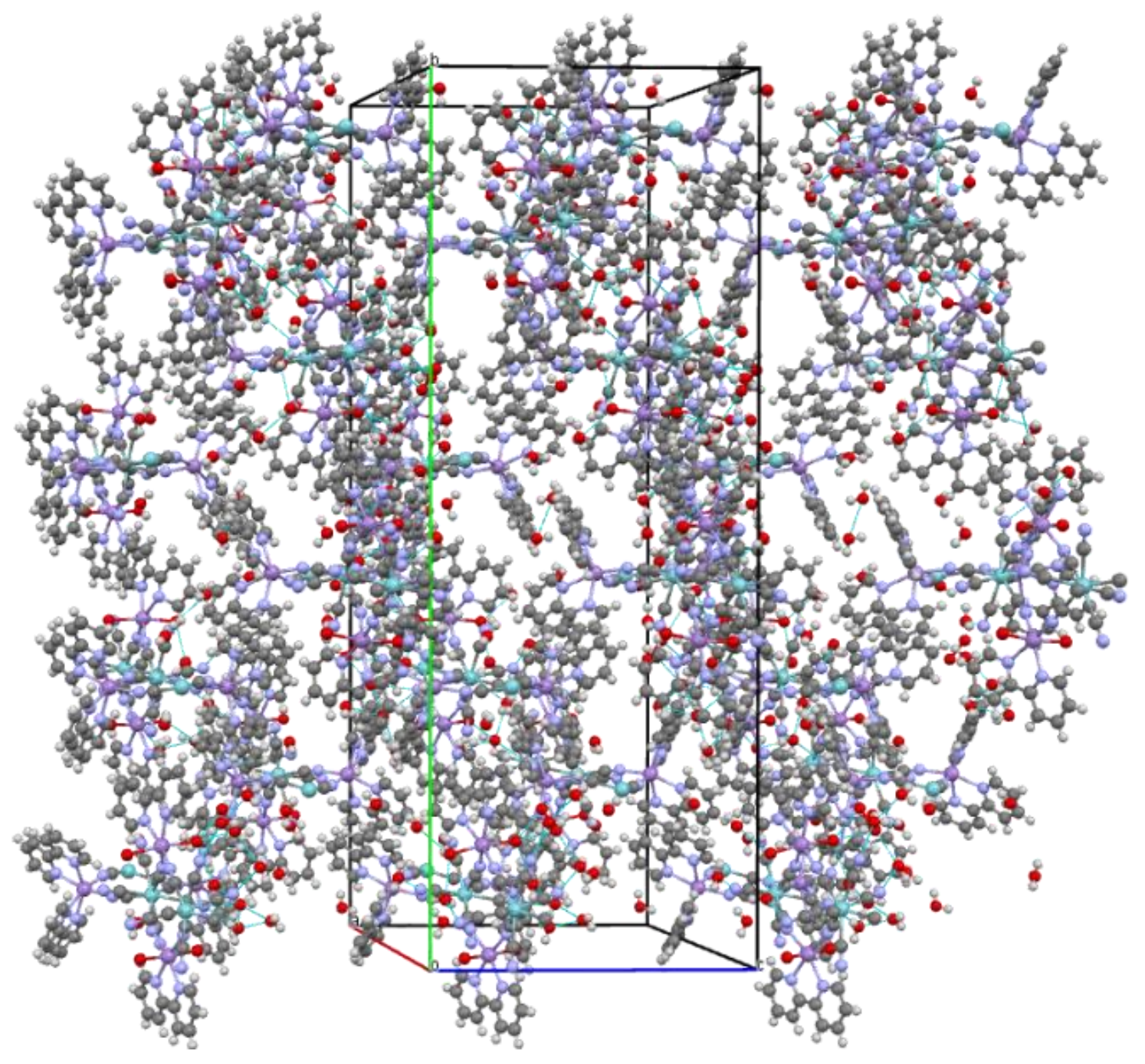


Figure S7. Fragments of structure of 2, showing H-shaped hydrogen bonding patterns. Mn pink, $\mathrm{Nb}$ - cyan, $\mathrm{C}$ - gray, $\mathrm{N}$ - blue, $\mathrm{O}$ - red.

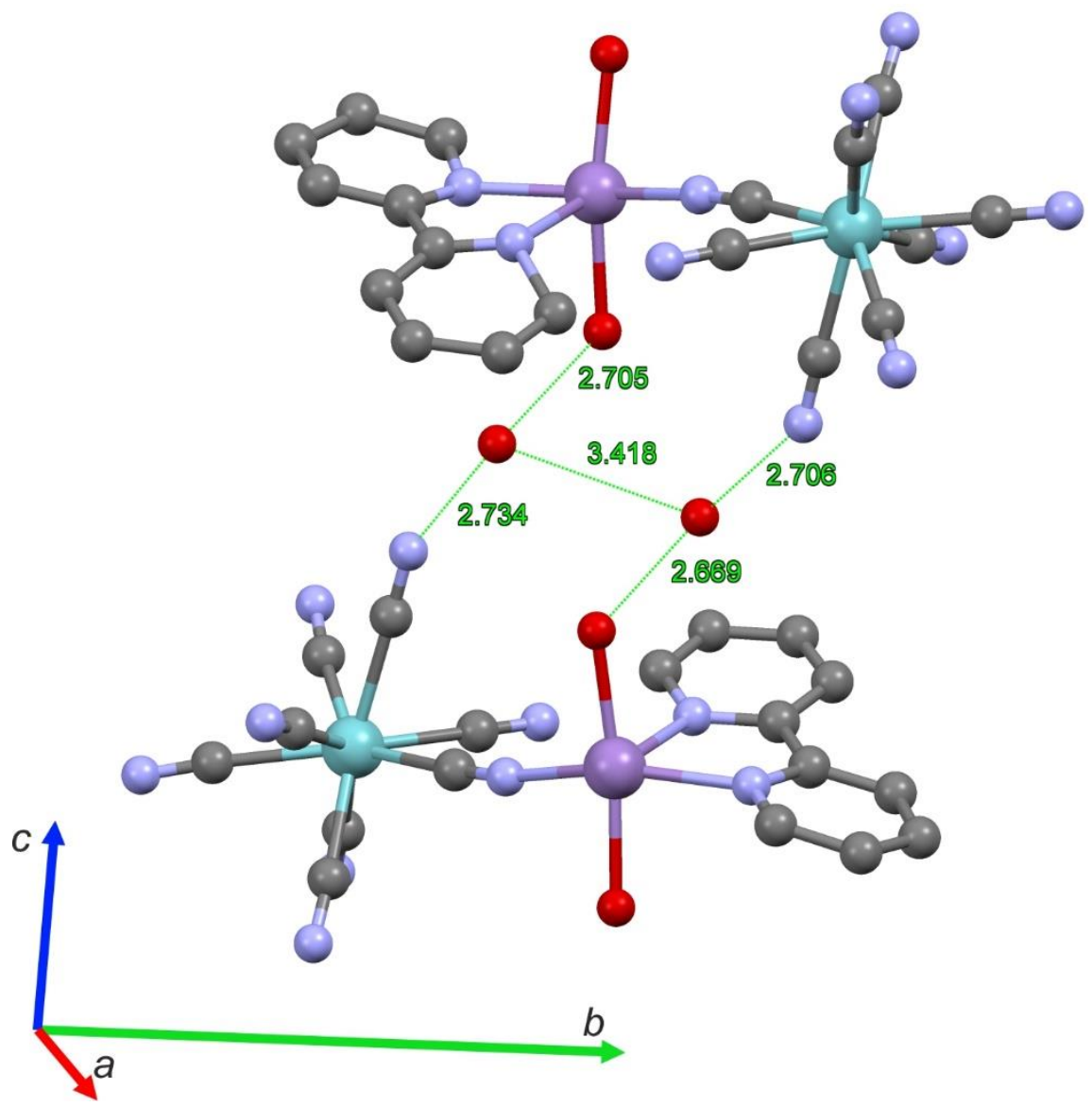


Figure S8. Fragments of structure of 2, showing intrachain hydrogen bonding interactions. Mn - pink, $\mathrm{Nb}$ - cyan, $\mathrm{C}$ - gray, $\mathrm{N}$ - blue, $\mathrm{O}$ - red.

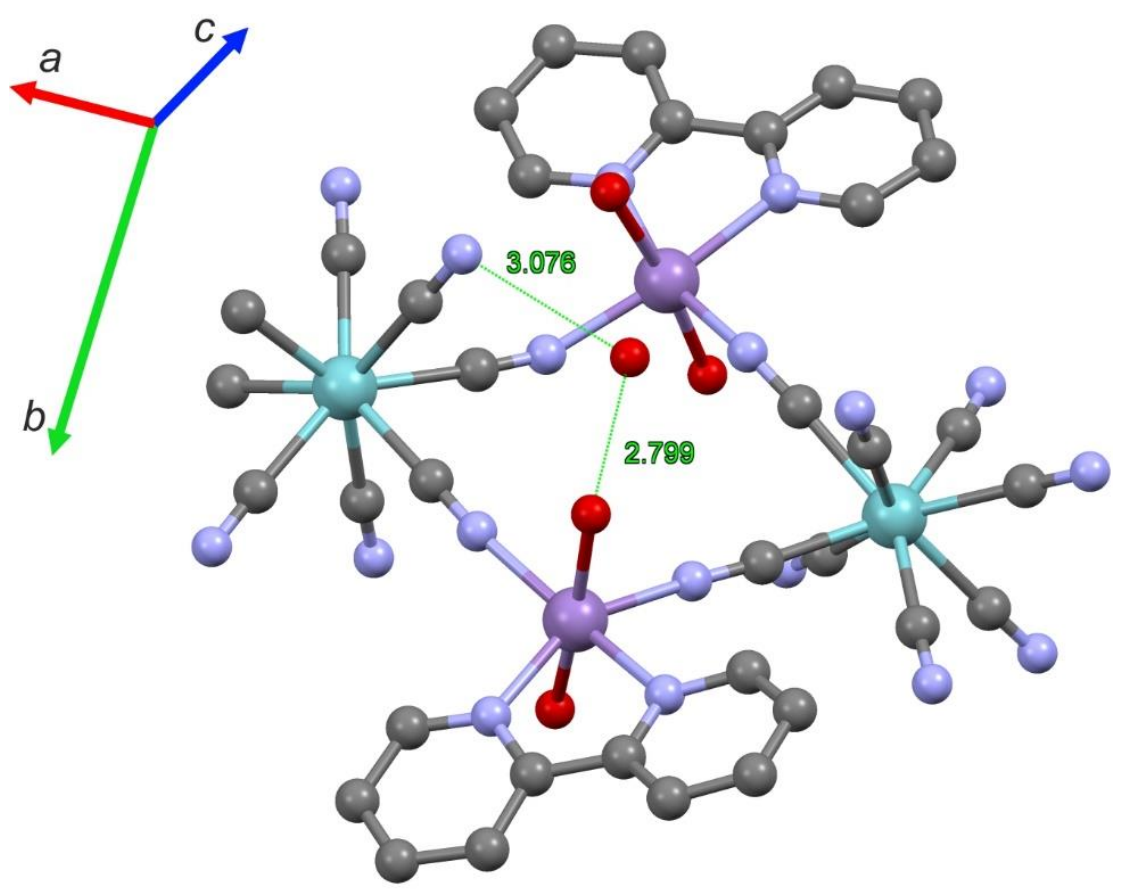


Figure S9. Fragments of structure of $\mathbf{2}$, showing $\pi-\pi$ interactions between chains. Crystallization water molecules and hydrogen atoms were omitted for clarity. $\mathrm{Mn}$ - pink, $\mathrm{Nb}$ - cyan, $\mathrm{C}-$ gray, $\mathrm{N}$ - blue, $\mathrm{O}$ - red.

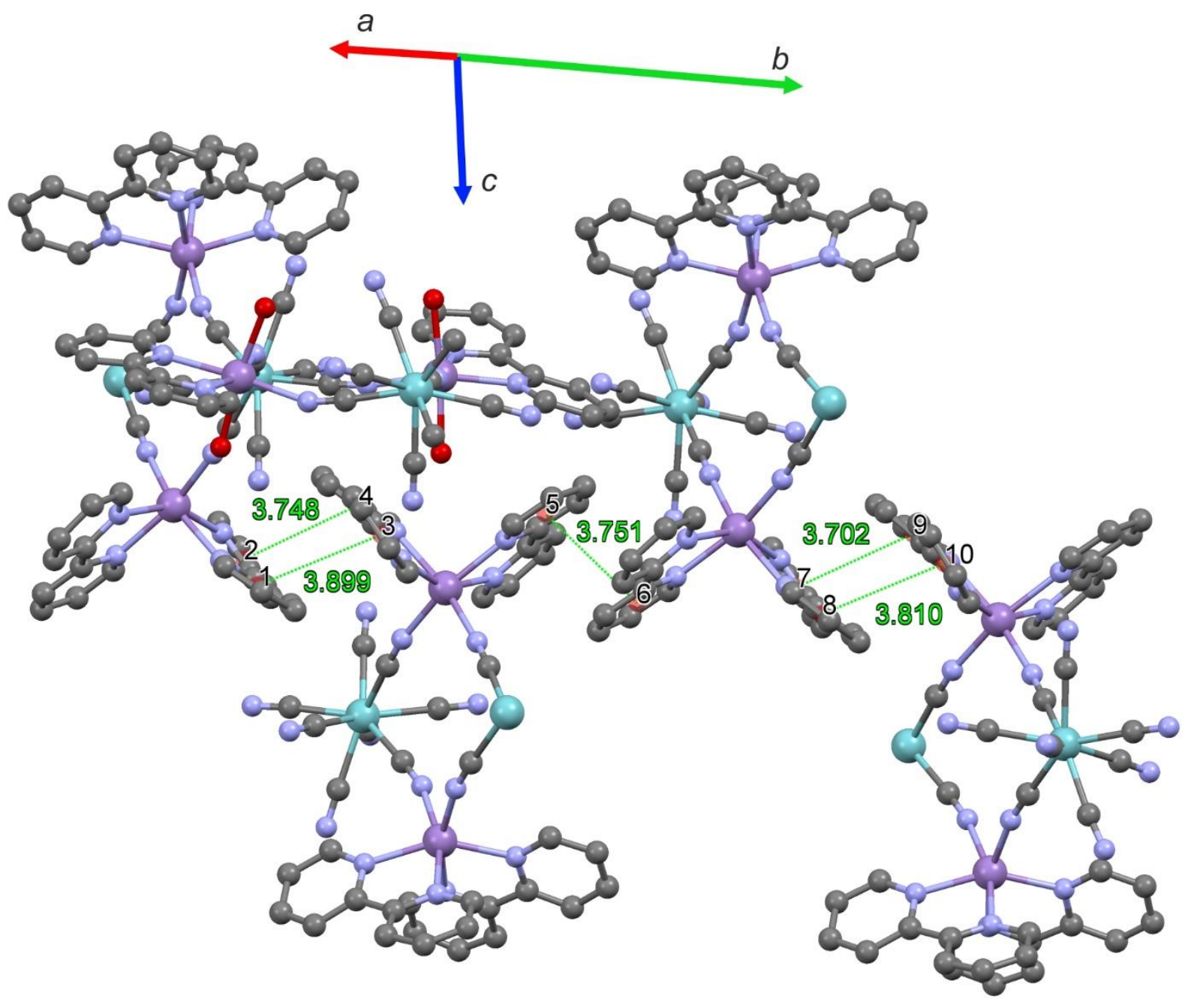


Figure S10. Results of the AC magnetic susceptibility measurements for compound $\mathbf{1}\left(H_{\mathrm{AC}}=\right.$ $\left.1.5 \mathrm{Oe}, H_{\mathrm{DC}}=0 \mathrm{Oe}\right)$.

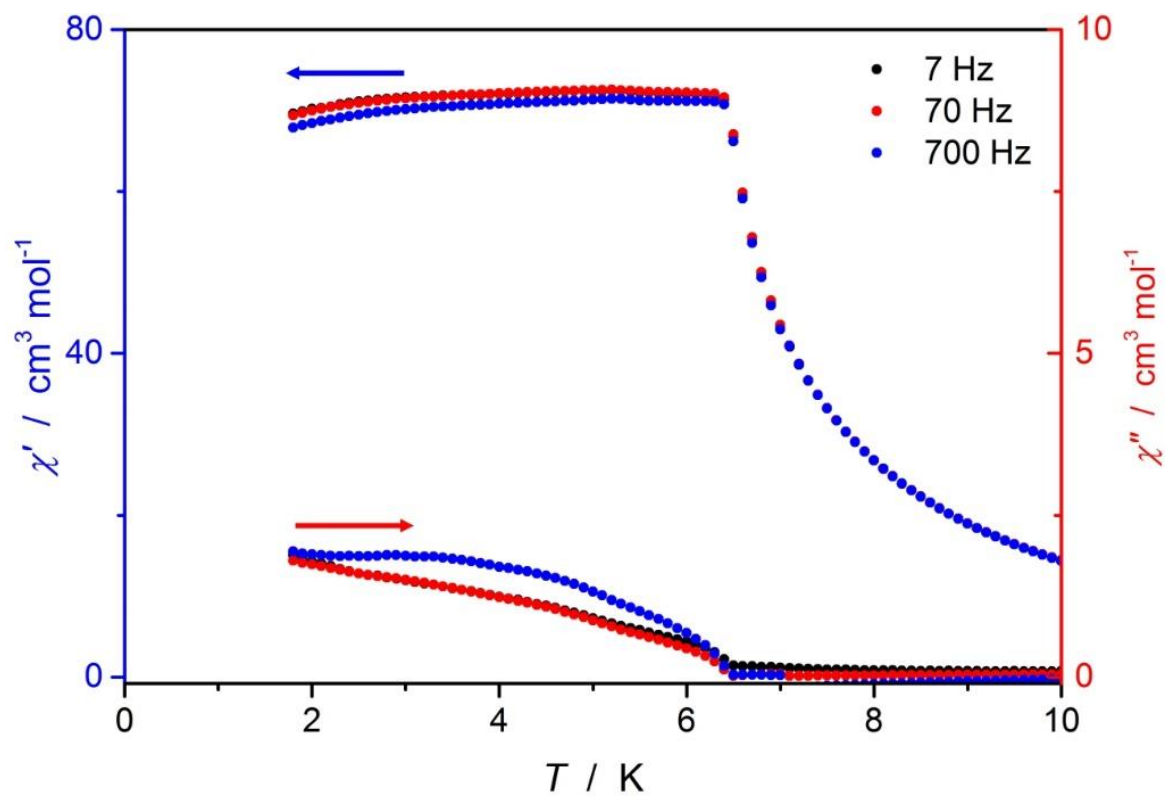

Figure S11. Results of the AC magnetic susceptibility measurements for compound $2\left(H_{\mathrm{AC}}=\right.$ $\left.1.5 \mathrm{Oe}, H_{\mathrm{DC}}=0 \mathrm{Oe}\right)$.

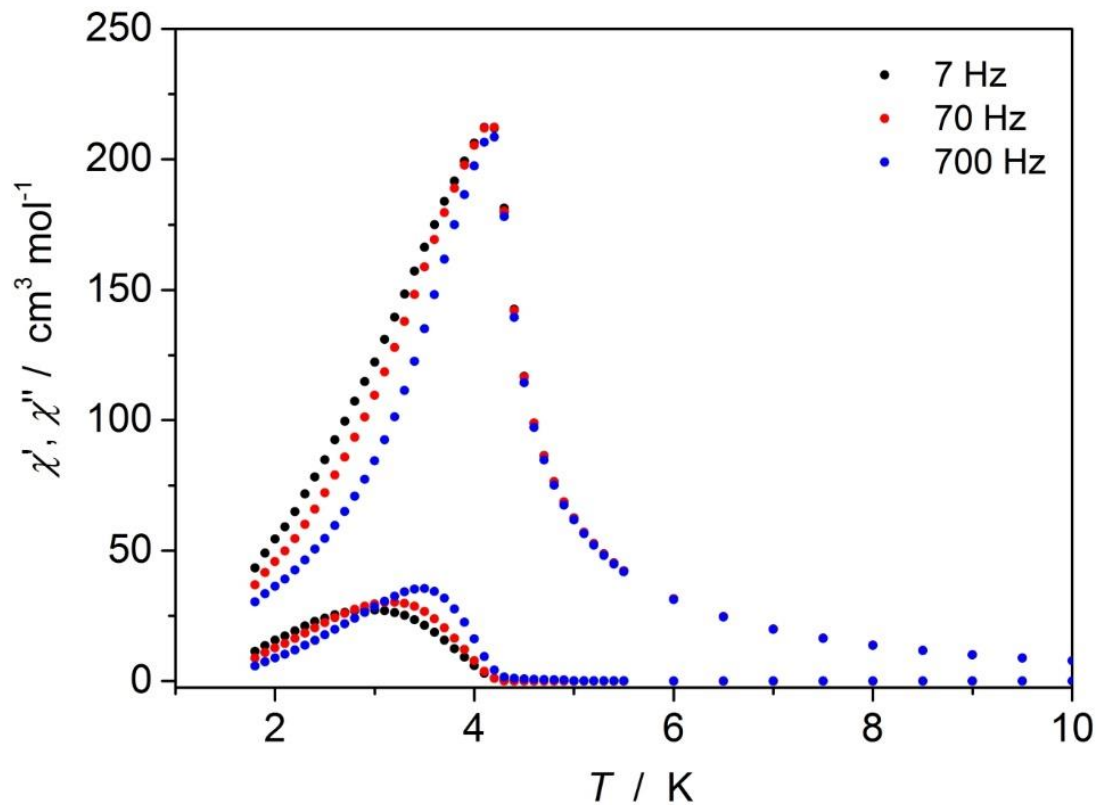


Figure S12. (a) $\chi^{-1}(T)$ dependence for 1 (black) and 2 (red) with Curie-Weiss fits in $200-300$ $\mathrm{K}$ range (dotted lines) and the best fits to the model described in the text in the $50-300 \mathrm{~K}$ range (solid lines); (b) the scheme showing how the $-\mathrm{Mn}_{2}-\mathrm{Nb}-\mathrm{Mn}_{2}-\mathrm{Nb}-$ molecule has been closed into a loop in order to approximate the magnetic behaviour of an infinite $-\mathrm{Mn}_{2}-\mathrm{Nb}-$ chain at temperatures above $50 \mathrm{~K}$.
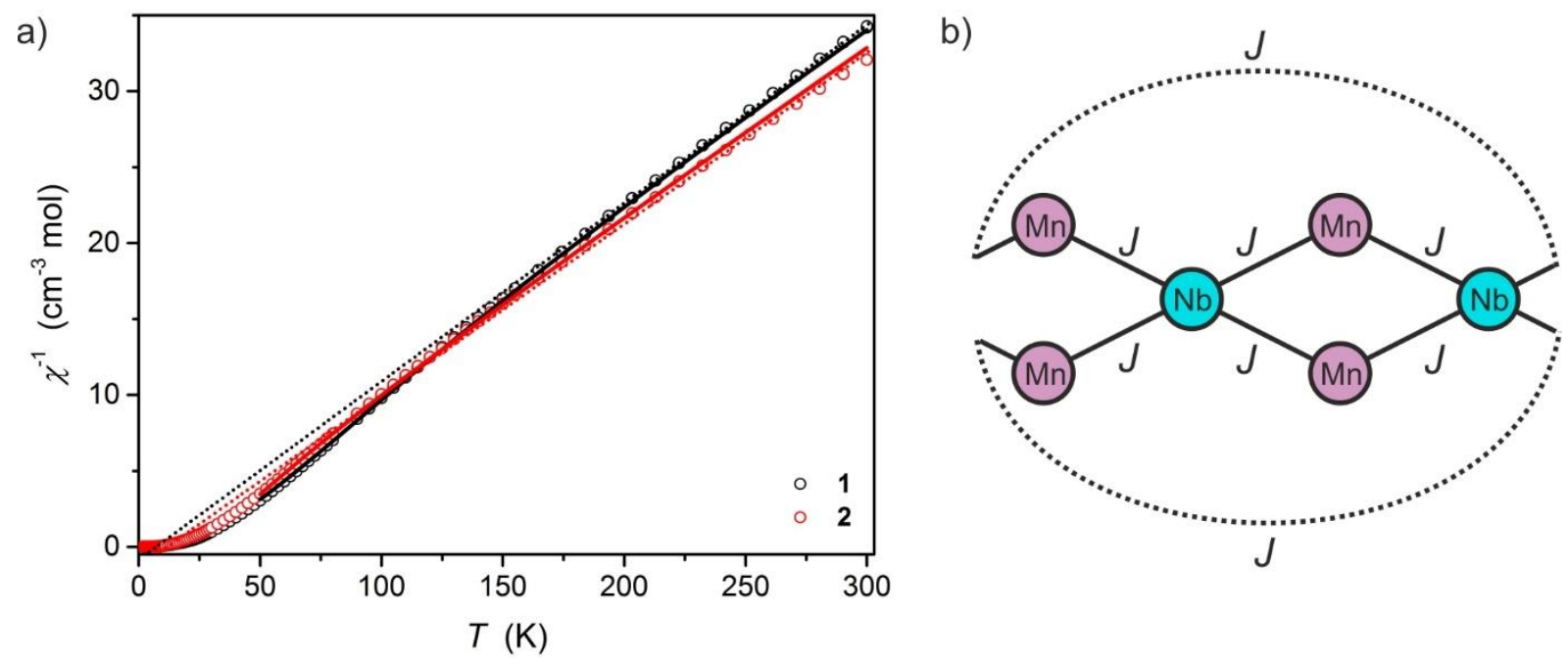